\title{
Human Papillomavirus Infection, Centrosome Aberration, and Genetic Stability in Cervical Lesions
}

\author{
Barbro Skyldberg, Kaoru Fujioka, Ann-Cathrin Hellström, Lisskulla Sylvén, Birgitta Moberger, Gert Auer \\ Division of Cellular and Molecular Tumor Pathology (BS, KF, GA), Department of Oncology-Pathology, \\ Cancer Center Karolinska, Karolinska Institutet, Karolinska Hospital; Division of Biomedical Laboratory \\ Technology (BS), Department of Immunology, Microbiology, Pathology and Infectious Diseases, Karolinska \\ Institutet, Huddinge Hospital; Division of Gynecological Oncology (A-CH), Department of Oncology- \\ Pathology, Karolinska Institutet, Karolinska Hospital; Division for Obstetrics and Gynecology (LS, BM), \\ Department of Woman and Child Health, Karolinska Institutet, Karolinska Hospital, Stockholm, Sweden
}

DNA replication and centrosome duplication have to be strictly synchronized to guarantee genomic stability. p53, pRb, cyclin E, and cyclin A are reported to be involved in the synchronizing process. We investigated the relationship between papillomavirus infection, centrosome aberration and aneuploidy during genesis of cervical carcinoma. The number of centrosomes found in cells from normal cervical epithelium $(n=5)$, condyloma acuminata $(n=5)$, cervical intraepithelial neoplasia (CIN) I, II, and III $(n=14)$ and invasive cervical carcinoma $(n=5)$ was analyzed by $\gamma$ tubulin immunofluorescence staining. The nuclear DNA content was investigated by image cytometry and human papillomavirus (HPV) infection was determined by polymerase chain reaction. Normal epithelia and condyloma acuminata showed cells with one or two centrosomes, whereas CIN lesions showed cells with an increasing number of centrosomes. This abnormality was found to be lowest in CIN I lesions, increased with advancing grade of CIN and was highest in lesions of invasive carcinomas. In parallel, an increasing number of cells with aberrant DNA content was seen. All carcinomas and all except one of the CIN III lesions showed aneuploidy. Three CIN II cases were aneuploid and two cases with CIN I were tetraploid. Normal epithelia and condyloma acuminata showed diploidy. All invasive carcinomas and lesions with CIN were positive for high-risk HPV types 16, 18, or 31, except one invasive carcinoma and one CIN II lesion positive for universal primers only. Three condyloma acuminata were HPV 16-positive and one HPV 6-positive.

Copyright () 2001 by The United States and Canadian Academy of Pathology, Inc.

VOL. 14, NO. 4, P. 279, 2001 Printed in the U.S.A.

Date of acceptance: October 24, 2000.

Address reprint requests to: Barbro Skyldberg, Cancer Center Karolinska (CCK), R8:04, Karolinska Hospital, SE-171 76 Stockholm, Sweden; e-mail: Barbro.Skyldberg@impi.ki.se; fax: 46-8-7283688.
The results suggest that high-risk HPV infection is correlated to a progressive numerical disturbance of centrosome replication followed by progressive chromosomal aberrations in CIN lesions and invasive carcinomas.

KEY WORDS: Cervical lesions, HPV, Centrosomes, Genetic stability.

Mod Pathol 2001;14(4):279-284

It has been shown in 1996 by Fukasawa et al. (1) that in mouse cells lacking the p53 tumor suppressor protein numeric centrosome aberration occurs during the cell cycle. Loss of p53 may cause genetic instability in the cells by unequal segregation of chromosomes during mitosis due to centrosome overproduction (1). Genetic instability is frequently occurring in malignant tumors and is often characterized by an abnormal number of chromosomes and aneuploidy (2-5).

The centrosomes are the main microtubule organizing centers in animal cells. The demonstration of the highly organized centrosomes and the characterization of their functions together with studies implicating centrosomes in tumorigenesis has brought this earlier not well-known organelle into focus (6). Recently, Cdk2-cyclin E was identified in Xenopus egg extracts by two independent groups as a trigger that helps the dividing cell to copy its centrosome $(7,8)$. Cdk2, when activated by cyclin $\mathrm{E}$ has been shown to help to drive the somatic cells through the division cycle, from G1 to S phase (9), which is the time during the cell cycle when centrosome duplication starts. The centrosome duplicates only once during each cell cycle and duplication is completed in G2 (10). Recently it has been shown by Matsumoto et al. (11) that Cdk2 is required for centrosome duplication in mammalian cells and by Meraldi and coworkers (12) that centrosomal replication in mammalian somatic cells is 
strictly dependent on phosphorylation of the retinoblastoma $(\mathrm{Rb})$ protein and requires the activation of E2F transcription factors, as well as Cdk2 and cyclin A activity. The E7 proteins of high-risk human papillomavirus (HPV) types, e.g., 16 and 18, have been demonstrated to form a complex with the $\mathrm{pRb}$ and to interfere with the binding of $\mathrm{pRb}$ to E2F transcription factors $(13,14)$. "The balance in the genome is maintained through the centrosomal machinery" according to Robert Palazzo (15), and if a centrosome replicates too often or fails to replicate, the daughter cells can get abnormal chromosomal compositions, which can predispose the cells to cancer. Recently, researchers have found that cancer cells, have abnormal numbers of centrosomes (16).

The purpose of the present study was to investigate the relationship between HPV infection, centrosome aberration and aneuploidy during genesis of cervical carcinoma. The results show that increasing grades of cervical intraepithelial neoplasia (CIN) are paralleled by increasing numbers of centrosomes in a subset of epithelial cells as well as aneuploidy. We suggest that high-risk HPV infection, correlated to a progressive numerical disturbance of centrosome replication, followed by centrosomal aberration and aneuploidy is crucial for the origin of a majority of cervical carcinomas.

\section{MATERIALS AND METHODS}

\section{Preparation of Imprints from Fresh Tissues for Immunofluorescence Staining and Feulgen \\ Staining for Ploidy Analyses}

Imprints were prepared from surgical resection specimens of normal epithelial tissue, condyloma acuminata lesions, CIN I, II, and III lesions, and invasive carcinomas from uterine cervix. Informed consent was obtained from each patient. The fresh tissue specimens were kept on dry ice until the imprints were made on slides. The imprints for immunostaining were then stored in methanol at $-20^{\circ} \mathrm{C}$. The imprints for ploidy analyses by image cytometry first were air-dried and then fixed overnight in $4 \%$ buffered formaldehyde before staining, which procedure, internal standardization and tumor cell selection were based on methods described earlier (17). All DNA values were expressed in relation to the corresponding staining controls, which were given the value $2 \mathrm{c}$, denoting the normal diploid DNA content. All DNA values were presented in such relative units.

After the preparation of imprints the biopsies were fixed in $4 \%$ buffered formaldehyde, paraffinembedded and stained for histopathologic evaluation. Each histopathologic diagnosis was based on the judgment of two pathologists blinded to laboratory results.

\section{Antibodies}

As $\gamma$ tubulin is a major component of centrosome matrix, monoclonal mouse antibodies to $\gamma$ tubulin (Sigma, St. Louis, MO) diluted 1:500 (PBS with 2\% normal goat serum) and as secondary antibodies FITC-conjugated anti-mouse Ig-G from goat (Sigma) diluted 1:128 in (PBS with $2 \%$ normal goat serum) were used. DNA was visualized by staining with DAPI (4',6-diamino-2-phenylindole, Sigma).

\section{Immunofluorescence Staining for $\gamma$ Tubulin}

The imprints were fixed in methanol for shortest time $10 \mathrm{~min}$ at $-20^{\circ} \mathrm{C}$ and then in acetone for $6 \mathrm{~min}$ at $-20^{\circ} \mathrm{C}$, washed with PBS pH 7.2 twice for $5 \mathrm{~min}$ each, blocked with $1 \%$ normal goat serum in PBS with $0.1 \%$ Tween 20 , washed again with PBS three times for 5 min each and then incubated with the monoclonal antibodies for 2 hours at $37^{\circ} \mathrm{C}$. After incubation with secondary antibodies for 1 hour at room temperature in dark, the specimens were washed with PBS three times for 5 min, incubated with DAPI solution for $5 \mathrm{~min}$ at room temperature, washed with PBS again for 5 min, mounted with one drop mounting medium (Vectashield, Vector Laboratories, Burlingame, California) and covered with a coverslip. The immunofluorescence staining was evaluated with a fluorescence microscope, Zeiss Axioskop and the number of centrosomes $(=\gamma$ tubulin stained spots) were counted in 100 cells of each specimen.

\section{Extraction of DNA for Polymerase Chain Reaction (PCR)}

The fresh tissue samples were cut into small pieces. Then $500 \mu \mathrm{L}$ of lysisbuffer (10 mm Tris HCL pH 7.6, 1 mм EDTA pH 8.0, 1\% sodium dodecyl sulfate, $50 \mathrm{~mm} \mathrm{NaCl}$ ) and 400 to $600 \mu \mathrm{g}$ proteinase $\mathrm{K} / \mathrm{mL}$ buffer were added to every sample in an Eppendorf tube and were incubated overnight at $50^{\circ} \mathrm{C}$. After that $500 \mu \mathrm{L}$ phenol:chloroform:isoamylalcohol (25:24:1) were added and shaken carefully on a shaker for $10 \mathrm{~min}$ before centrifugation at $13,000 \mathrm{rpm}$ for $15 \mathrm{~min}$ in an Eppendorf centrifuge. The water phase was taken and the former steps were repeated once. Then chloroform:isoamylalcohol (24:1) were added $1: 1$ and shaken carefully for 5 min, centrifugated $13,000 \mathrm{rpm}$ for $5 \mathrm{~min}$ and this was repeated once. The water phase was moved to a new tube; two volumes (about $1 \mathrm{~mL}$ ) ice-cold 95\% ethanol and $3 \mathrm{~m} \mathrm{NaAc} \mathrm{pH} 5.2$ to a final concentration of $0.3 \mathrm{~m}$ were added and the tubes were stored overnight at $-20^{\circ} \mathrm{C}$ to precipitate the DNA. Finally they were centrifuged at $13,000 \mathrm{rpm}$ for $30 \mathrm{~min}$ 
before ice-cold $70 \%$ ethanol was added up to $1 \mathrm{~mL}$ and centrifuged again for $15 \mathrm{~min}$ at the same rate to take the phenol away, After the DNA pellet was dried under vacuum, the DNA was dissolved in 20 to $30 \mu \mathrm{L}$ sterile distilled water and stored at $-20^{\circ} \mathrm{C}$ until PCR analyses was performed.

\section{PCR Analyses for HPV}

For universal detection of HPV two sets of universal or consensus primer pairs from the highly conserved Ll region were used, one degenerated pair, My 11 and My 09, of Manos and coworkers (18), PCR procedures described in detail (19) and one nondegenerated pair, GP5 + and GP6 + of Husman et al. (20), PCR procedures described in detail (5). Type-specific HPV primers for HPV 6, 16, 18, 31, and 33 from E5-E6-E7 gene regions were used according a procedure described earlier (21). For analysis of the PCR product, $15 \mu \mathrm{L}$ of the amplified product was run on a $3 \%$ agarose gel and stained with ethidium bromide $(0.5 \mu \mathrm{g} / \mathrm{mL})$. As a control of DNA extraction, a set of HLA DQ primers i.e., GH26/27 (22) was used.

\section{RESULTS}

Table 1 summarizes the results of HPV detection, numbers of centrosomes and DNA ploidy measurements in fresh tissue specimens from uterine cervix with the histopathologic diagnoses of normal cervical epithelium, condyloma, CIN I, CIN II, CIN III, and cervical carcinoma.

\section{PCR Analyses for HPV}

All cervical carcinomas and lesions with CIN were HPV-positive, infected with high-risk types HPV 16, 18 , or 31 . Two of the cases, one adenosquamous cancer and one lesion with CIN II, were positive for the universal GP primers, but none of the type specific primers used. Three of the condylomas were HPV 16-infected. One of the condyloma acuminata lesions, a vulvar condyloma, was HPV 6-positive, and one was unexpectedly negative with both sets of the universal primers. One of the normal cases was HPV 16-positive.

\section{$\gamma$ Tubulin Detection}

All the invasive carcinomas ( $n=5)$ and CIN III ( $n$ $=5)$ and most of the CIN II $(n=5)$ lesions had abnormal numbers of centrosomes. This abnormality was found to be highest in invasive carcinomas (present in up to $11 \%$ of the cells) and decreased with decreasing grade of CIN (Fig. 1). One of the lesions with CIN II had no centrosomal aberration, and was hard to diagnose, it was judged as meta-

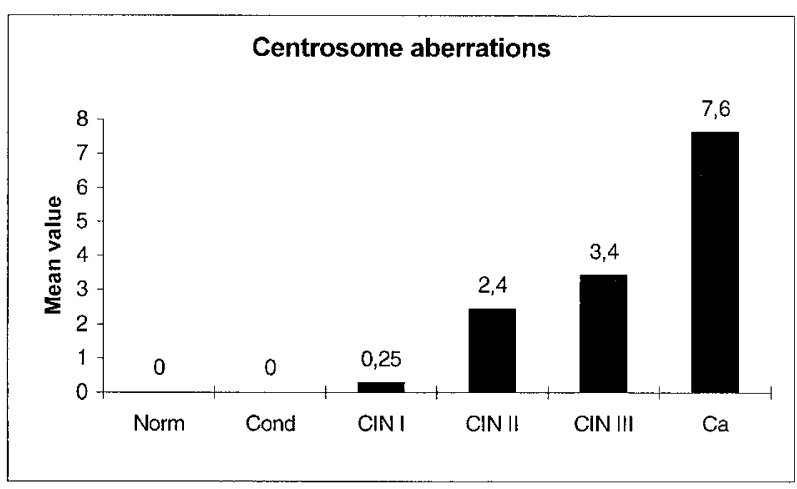

FIGURE 1. Numerical centrosomal aberrations in normal cervical epithelium and various cervical lesions. $\mathrm{x}$-axis: type of cervical lesion; $\mathrm{y}$-axis: mean value of numerical centrosome aberrations. CIN, cervical intraepithelial neoplasia.

plasia or CIN II by different pathologists at different occasions. Only one of the lesions with CIN I ( $n=$ 4) showed centrosomal aberrations (in $1 \%$ of the cells). None of the condylomas $(n=5)$ or normal cases $(n=5)$ had centrosomal aberrations.

\section{DNA Ploidy Measurements}

The DNA content histograms were evaluated by subdividing the profiles subjectively into three main categories: 1) Diploid (profiles with a main peak in the normal diploid region). 2) Tetraploid (profiles with a main peak in the tetraploid region). 3) Aneuploid (profiles with one or more peaks outside the diploid or tetraploid regions). All of the carcinomas and all except one of the lesions with CIN III showed aneuploidy (Fig. 2). This lesion showed a tetraploid DNA pattern and unfortunately HPV analysis was not able to perform in this case. Two of the cases with CIN II showed diploidy and two cases with CIN I showed a tetraploid DNA pattern. All the condylomas and normal cases were diploid. Age of the individual cases is reported in Table 1.

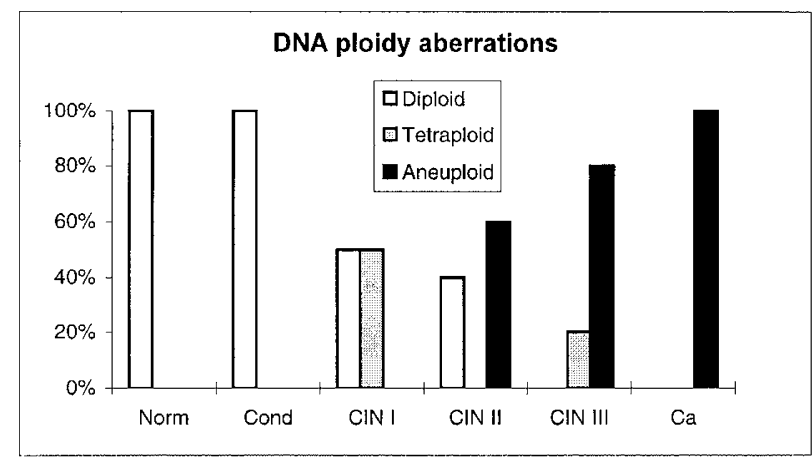

FIGURE 2. DNA ploidy of normal cervical epithelium and various cervical lesions. Percentage of diploid, tetraploid, and aneuploid specimens in normal cervical epithelium $(n=5)$, condyloma acuminata $(n=5)$, CIN I $(n=4)$, CIN II $(n=5)$, CIN III $(n=5)$, cervical carcinoma $(n=5)$. CIN, cervical intraepithelial neoplasia. 
TABLE 1. Patient Age, HPV Status, Numerical Centrosomal Aberrations, and DNA Ploidy in Normal Cervical Epithelium and Various Cervical Lesions

\begin{tabular}{|c|c|c|c|c|}
\hline Normal Cervix & $\begin{array}{c}\text { Age } \\
\text { (Years) }\end{array}$ & $\begin{array}{c}\text { HPV } \\
\text { Positivity }\end{array}$ & $\begin{array}{l}\text { Numerical } \\
\text { Centrosomal } \\
\text { Aberrations } \\
>2(\%)\end{array}$ & $\begin{array}{c}\text { DNA } \\
\text { Ploidy }\end{array}$ \\
\hline 1 & 59 & HPV 16 & 0 & $\mathrm{D}$ \\
\hline 2 & 54 & Neg & 0 & $\mathrm{D}$ \\
\hline 3 & 57 & Neg & 0 & $\mathrm{D}$ \\
\hline 4 & 51 & Neg & 0 & $\mathrm{D}$ \\
\hline 5 & 56 & Neg & 0 & $\mathrm{D}$ \\
\hline \multicolumn{5}{|l|}{ Condyloma } \\
\hline 1 & 36 & HPV 6 & 0 & $\mathrm{D}$ \\
\hline 2 & 35 & HPV 16 & 0 & $\mathrm{D}$ \\
\hline 3 & 21 & HPV 16 & 0 & $\mathrm{D}$ \\
\hline 4 & 51 & HPV 16 & 0 & $\mathrm{D}$ \\
\hline 5 & 35 & Neg & 0 & $\mathrm{D}$ \\
\hline \multicolumn{5}{|l|}{ CIN I } \\
\hline 1 (cond) & 35 & HPV 16 & 0 & $\mathrm{D}$ \\
\hline 2 & 57 & HPV 16 & 0 & $\mathrm{~T}$ \\
\hline 3 & 30 & HPV 16 & 0 & $\mathrm{D}$ \\
\hline 4 & 25 & HPV 16 & 1 & $\mathrm{~T}$ \\
\hline \multicolumn{5}{|l|}{ CIN II } \\
\hline 1 & 22 & HPV 16 & 1 & A \\
\hline 2 & 42 & HPV 16 & 6 & $\mathrm{D}$ \\
\hline 3 (metapl) & 30 & HPV 16 & 0 & A \\
\hline 4 & 42 & HPV pos(GP) & 4 & A \\
\hline 5 & 42 & HPV 16 & 1 & $\mathrm{D}$ \\
\hline \multicolumn{5}{|l|}{ CIN III } \\
\hline 1 & 57 & HPV 18 & 2 & A \\
\hline 2 & 30 & HPV 16 & 3 & A \\
\hline 3 & 30 & HPV 16 & 5 & A \\
\hline 4 & 38 & N.D. & 4 & $\mathrm{~T}$ \\
\hline 5 & 31 & HPV 16 & 3 & A \\
\hline \multicolumn{5}{|l|}{ Cervical ca } \\
\hline 1 & 41 & HPV 16 & 11 & A \\
\hline 2 & 26 & HPV 16 & 3 & A \\
\hline 3 & 48 & HPV 31 & 8 & A \\
\hline 4 & 74 & HPV pos(GP) & 5 & A \\
\hline 5 & 52 & HPV 18 & 11 & A \\
\hline
\end{tabular}

$>2$, more than two; D, diploid; T, tetraploid; A, aneuploid; N.D., not determined; GP, GP primers; HPV, human papillomavirus; CIN, cervical intraepithelial neoplasia.

\section{DISCUSSION}

Our results show that cells in normal epithelia and condyloma from the uterine cervix contain only one or two centrosomes whereas lesions with advancing grades of CIN exhibit increasing numbers of cells with more than two centrosomes. The highest percentage of cells with more than two centrosomes was observed in invasive cervical cancer. In parallel with increasing numbers of centrosomes an increasing number of cells with aneuploidy was seen. The present data indicate the connection between the severity of the lesions, centrosome aberration and aneuploidy. Thus progression from CIN I to CIN II, CIN III, and invasive carcinoma seems to be related to increasing numbers of cells with abnormal centrosome replication and increasing aberration of the normal diploid DNA pattern. Pihan et al. found 1998 in different types of malignant tumors and cell lines that the centrosomes were atypical in shape and size and increased in number and they suggested that these conditions may contribute to genetic instability (16). As early as 1914, Boveri in "The origin of malignant tumors" (23) suggested that the centrosome, "a pair of centrioles surrounded by a differentiated cytoplasm," might be a key to cancer. This cytoplasm or pericentriolar material has been shown by advanced immunofluorescence imaging to consist of a variety of specific centrosome proteins e.g., pericentrin organized into a highly ordered lattice structure and $\gamma$ tubulin, a protein component of the centrosome essential for microtubule polymerization, co-localized with pericentrin to this lattice (24-26). By means of electron microscopy the centrosome lattice structures have also been demonstrated in different organisms (27-29).

In 1991 Levine et al. reported that formation of tetraploid intermediates is associated with the development of cells with more than four centrioles in the development of pancreatic cancer in transgenic mice expressing the simian virus 40 tumor antigen (30), which is one of the viral oncoproteins known to interact with p53 (31). Furthermore, Levine et al. observed that in ulcerative colitis with dysplasia or cancer genomic instability and clonal evolution of aneuploid cells were associated with malignancy progression (32). Today it is generally accepted that most solid cancers are genetically unstable $(3,33)$. One of the causal factors of genetic instability has been shown to be the tumor suppressor protein, p53, whose function in cells and tissues can be reduced or abolished by e.g., loss and mutations of the p53 gene, which is common in many human cancers, e.g., colon, lung, breast and liver cancers (34), or by interaction with viral oncoproteins such as Simian virus 40 tumor antigen, adenovirus E1b and HPV E6 protein $(31,35)$. In cervical carcinomas low frequencies of p53 mutations have been reported and several studies have suggested p53 complexing with E6 protein of high-risk HPV types such as 16 and 18 and others as a causative agent of at least $90 \%$ of cancers of the uterine cervix (36-38). Beside the well known function of p53 in growth regulation after DNA damage it also has been demonstrated to regulate normal centrosome duplication $(1,39)$.

These previous observations are in accordance with our findings. It is suggested that the E6 protein of the high-risk HPV types, effectively inactivates p53 and that the E7 protein inactivates pRb, resulting in release of E2F transcription factors. This may lead to a disturbance of the synchronous start of DNA replication and centrosome duplication followed by progressive chromosomal aberrations in the CIN lesions and invasive cancers. There was just one of four CIN I lesions, all of them HPV 16infected, which had a centrosome aberration. This case showed a disturbance in the DNA pattern too, 
from diploid to tetraploid and even to an octaploid pattern. This point at the fact that it will take time for the virus to affect the centrosome replication and that the virus-associated morphologic changes could be detected before the DNA pattern have been disturbed. Three of five cases with condyloma acuminata were unexpectedly HPV 16-positive, and only one of them was, as expected, HPV 6-positive. This case was diagnosed as a vulvar condyloma. The other cases were suggested to be flat condylomas from the uterine cervix, invisible to the human eye, usually detected by the acetic acid test and generally HPV 16- or 18-positive. These condylomas may progress to malignant lesions, e.g., if the immune defense is decreased and the infection time is long enough.

We suggest that the high genomic stability that is characteristic of normal cervical epithelia and also lesions of condyloma is well correlated to normal centrosome replication, whereas the increasing genomic instability in CIN lesions and invasive carcinomas with high-risk HPV infection is correlated to disturbed centrosome replication, impaired chromosome segregation, and aneuploidy.

\section{REFERENCES}

1. Fukasawa K, Choi T, Kuriyama R, Rulong S, Vande Woude GF. Abnormal centrosome amplification in the absence of p53. Science 1996;271:1744-7.

2. Hartwell L. Defects in a cell cycle checkpoint may be responsible for the genomic instability of cancer cells. Cell 1992;71:543-6.

3. Hartwell L, Kastan MB. Cell cycle control and cancer. Science 1994;266:1821-8.

4. Lengauer C, Kinzler KW, Vogelstein B. Genetic instability in colorectal cancers. Nature 1997;386:623-7.

5. Skyldberg BM, Murray E, Lambkin H, Kelehan P, Auer GU. Adenocarcinoma of the uterine cervix in Ireland and Sweden: human papillomavirus infection and biological alterations. Mod Pathol 1999;12:675-82.

6. Zimmerman W, Sparks CA, Doxsey SJ. Amorphous no longer: the centrosome comes into focus. Curr Opin Cell Biol 1999; $11: 122-8$

7. Hincliffe EH, Li C, Thompson EA, Maller JL, Sluder G. Requirement of Cdk2-Cyclin E activity for repeated centrosome reproduction in Xenopus egg extracts. Science 1999;283:851-4.

8. Lacey KR, Jackson PK, Stearns T. Cyclin-dependent kinase control of centrosome duplication. Proc Natl Acad Sci USA 1999;90:2817-22.

9. Koff A, Giordano A, Desai D, Yamashita K, Harper JW, Elledge S, et al. Formation and activation of a cyclin E-cdk2 complex during the G1 phase of the human cell cycle. Science 1992;257:1689-94.

10. Brinkley BR. Microtubule organizing centers. Annu Rev Cell Biol 1985;1:145-72.

11. Matsumoto Y, Hayashi K, Nishida E. Cyclin-dependent kinase 2 (Cdk2) is required for centrosome duplication in mammalian cells. Curr Biol 1999;9:429-32.

12. Meraldi P, Lukas J, Fry AM, Bartek J, Nigg EA. Centrosome duplication in mammalian somatic cells requires E2F and Cdk2-cyclin A. Nat Cell Biol 1999;1:88-93.

13. Dyson N, Howley PM, Munger K, Harlow E. The human papillomavirus-16 E7 oncoprotein is able to bind to the retinoblastoma gene product. Science 1989;243:934-7.

14. Münger K, Phelps WC. The human papillomavirus E7 protein as a transforming and transactivating factor. Biochem Biophys Acta 1993;1155:111-23.

15. Palazzo RE, Vogel JM. Isolation of centrosomes from Spisula solidissima oocytes. Methods Cell Biol 1999;61:35-56.

16. Pihan GA, Purohit A, Wallace J, Knecht H, Woda B, Quesenberry $\mathrm{P}$, et al. Centro-some defects and genetic instability in malignant tumors. Cancer Res 1998;58:3974-85.

17. Auer GU, Heselmeyer KM, Steinbeck RG, Munck-Wikland E, Zetterberg $\mathrm{AD}$. The relationship between aneuploidy and p53 overexpression during genesis of colorectal adenocarcinoma. Virchows Arch 1994;424:343-7.

18. Manos MM, Ting Y, Wright DK, Lewis AJ, Broker TR. Use of polymerase chain reaction amplification for the detection of human papillomaviruses. Cancer Cells 1989;7:209-14.

19. Hagmar B, Platz-Christensen J-J, Johansson B, Kalantari M, Skyldberg B, Walaas L, et al. Implications of human papillomavirus type for survival in cervical squamous cell carcinoma. Int J Gynecol Cancer 1995;5:341-5.

20. de Roda Husman A-M, Walboomers JMM, van den Brule AJC, Meijer CJLM, Snijders PJF. The use of general primers GP5 and GP6 elongated at their 3'ends with adjacent highly conserved sequences improves human papillomavirus detection by PCR. J Gen Virol 1995;76:1057-62.

21. Skyldberg B, Kalantari M, Kärki M, Johansson B, Hagmar B, Walaas L. Detection of HPV infection in tissue blocks by in situ hybridization as compared to a PCR procedure. Hum Pathol 1991;22:578-82.

22. Ehrlich HA, Bugawan TL. HLA class II gene polymorphism: DNA typing, evolution, and relationship to disease susceptibility. In: Ehrlich HA, editor. PCR technology: principles and applications for DNA amplification. New York: Stockton Press; 1989. p. 193-208.

23. Boveri T, editor. The origin of malignant tumours. Baltimore: Williams and Wilkins; 1914.

24. Doxsey SJ, Stein P, Evans L, Calarco PD, Kirschner M. Pericentrin, a highly conserved centrosome protein involved in microtubule organization. Cell 1994;76:639-50.

25. Dietenberg JB, Zimmerman W, Sparks CA, Young A, Vidair C, Zheng Y, et al. Pericentrin and gamma-tubulin form a protein complex and are organized into a novel lattice at the centrosome. J Cell Biol 1998;141:163-74.

26. Oakley BR, Oakley CE, Yoon Y, Jung MK. Gamma-tubulin is a component of the spindle pole body that is essential for microtubule function in Aspergillus nidulans. Cell 1990;61: 1298-301.

27. Moritz M, Braunfeld MB, Sedat JW, Alberts B, Agard DA. Microtubule nucleation by gamma-tubulin-containing rings in the centrosome. Nature 1995;378:638-40.

28. Schnackenberg BJ, Khodjakov A, Rieder CL, Palazzo RE. The disassembly and reassembly of functional centrosomes in vitro. Proc Natl Acad Sci USA 1998;95:9295-300.

29. Thompson-Coffe C, Coffe G, Schatten H, Mazia D, Schatten G. Cold-treated centrosome: isolation of centrosomes from mitotic sea urchin eggs, production of an anticentrosomal antibody, and novel ultrastrutural imaging. Cell Motil Cytoskeleton 1996;33:197-207.

30. Levine DS, Sanchez CA, Rabinovitch PS, Reid BJ. Formation of the tetraploid intermediate is associated with the development of cells with more than four centrioles in the elastase-simian virus 40 tumor antigen transgenic mouse model of pancreatic cancer. Proc Natl Acad Sci USA 1991; 88:6427-31.

31. Vousden KH. Regulation of the cell cycle by viral oncoproteins. Semin Cancer Biol 1990;6:109-16.

32. Levine DS, Rabinovitch PS, Haggit RC, Blount PL, Dean PJ, Rubin CE, et al. Distribution of aneuploid cell populations in 
ulcerative colitis with dysplasia or cancer. Gastroenterology 1991;101:1198-1210.

33. Lengauer C, Kinzler KW, Vogelstein B. Genetic instabilities in human cancers. Nature 1998;396:643-9.

34. Hollstein M, Sidransky D, Vogelstein B, Harris CC. p53 mutations in human cancers. Science 1991;253:49-53.

35. Werness BA, Levine AJ, Howley PM. Association of human papillomavirus types 16 and 18 E6 proteins with p53. Science 1990;248:76-9.

36. Børresen AL, Helland A, Nesland J, Holm R, Trope C, Kaern J. Papillomaviruses, p53 and cervical cancer. Lancet 1992; 339:1350-1.
37. Busby-Earle RM, Steel CM, Williams AR, Cohen B, Bird CC. p53 mutations in cervical carcinogenesis-low frequency and lack of correlation with human papillomavirus status. Br J Cancer 1994;69:732-7.

38. zur Hausen H. Papillomavirus infections-a major cause of human cancers. Biochem Biophys Acta 1996;1288:F5578.

39. Weber RG, Bridger JM, Benner A, Weisenberger D, Ehemann $\mathrm{V}$, Reifenberger G, et al. Centrosome amplification as a possible mechanism for numerical chromosome aberrations in cerebral primitive neuroectodermal tumors with TP53 mutations. Cytogenet Cell Genet 1998;83:266-9. 